\section{Antenatal diagnosis and treatment of congenital adrenal hyperplasia due to 21-hydroxylase deficiency}

Sir,

Techniques of molecular biology have advanced to the point where we estimate that chorion villus biopsy can be informative for antenatal diagnosis of congenital adrenal hyperplasia due to 21 -hydroxylase deficiency in over $95 \%$ of cases. This offers the possibility of treating mothers, who have previously delivered an index patient, with dexamethasone to prevent ambiguity of the genitalia of a potentially affected female fetus.

We are now in a position to offer this service to clinicians who are invited to contact us if we can be of assistance to them.

T Strachan and D A Price St Mary's Hospital, Hathersage Road, Manchester M13 OJH

C G D Brook and G RumsBY Middlesex Hospital, Mortimer Street, London WIN 8AA

\section{Educating medical students about death and dying}

Sir,

I read with interest the paper by Black et al on educating medical students about death and dying. ${ }^{1}$

Most students recognise the need for a course which equips them to deal with the needs of dying patients and their families and the subject is clearly worthy of a place in the already packed undergraduate curriculum. It seems unfair, even unkind, for a junior doctor to have to go through the ordeal of a consultation with the family of a terminally ill patient if he has not had the advantage of prior experience.

In my preclinical psychology course the subject was touched upon and, even at that stage, provoked lively discussion and debate. However, it was the "communications course' which aroused the true feelings and emotions. This course is a challenging (and exhausting!) week of seminars, mini-lectures, group discussions, video teaching sessions, and role playing. Although aimed at learning general 'communication' skills-such as interviewing - the course inevitably included the setting of the terminally ill patient. Actors were brought in to help students learn about the breaking of bad news. Valuable feedback sessions enabled students to correct mistakes, such as distancing tactics, and to recognise scope for improvement.

Surely such a course is an essential component of the clinical curriculum. With the use of a range of teaching methods, medical students will have the chance to develop techniques in talking to dying patients and their families. Above all, the initial hurdle will have been jumped and the scene set for added understanding, trust and empathy in the doctor-patient relationship.

Reference
1 Black D, Hardoff D, Nelki J. Educating medical students about
death and dying. Arch Dis Child 1989:64:750-3.

M R BARRIE MEDICAL STUDENT

St Thomas's Hospital Medical School, London SEI 7EH 